3 Mauff G, Alper CA, Awdeh Z, et al. Statement on the nomenclature of human C4 allotypes. Immunobiology 1983;164:184-91.

4 Mijovic C, Fletcher J, Bradwell AR, Harvey T, Barnett AH. Relation of gene expression (allotypes) of the fourth component of complement to insulin dependent diabetes and its (allotypes) of the fourth component of complement to

5 Pandey JP, Whitten HD, Fudenberg HH. Genetics of human immunoglobulins. In: Panayi GS, David CS, eds. Immunogenetics. London: Butterworths, 1984:92-109.

6 Propert DN. Detection of immunoglobulin polymorphisms. In: Simons MJ, Tait BD, eds. Detection of immune-associated genetic markers of human disease. London: Churchill Livingstone, 1984:65-81.

7 Brown MB. Frequency tables-P4F. In: Dixon WJ, ed. BMDP statistical software, 1983. Berkeley: University of California Press, 1983

8 Mathews JD. Statistical aspects of immunogenetic associations with disease. In: Simons MJ, Tait BD, eds. Detection of immune associated genetic markers of human disease. London: Churchill Livingstone, 1984:106-36.

9 Nakao $\mathrm{Y}$, Matsumoto $\mathrm{H}$, Miyazaki T, et al. IgG heavy chain $(\mathrm{Gm})$ allotypes and immune response to insulin in insulin requiring diabetes mellitus. $N$ Engl f Med 1981;304:407-9.
10 Reeves WG, Barr D, Douglas CA, et al. Factors governing the human immune response to injected insulin. Diabetologia 1984;26:266-71.

1 Andersen OO. Anti-insulin antibodies and late diabetic complications. Acta Endocrinol 1976;83: $329-40$.

12 DiMario U, Ventriglia L, Iavicoli M, Guy K, Andreani D. The correlation between insulin antibodies and circulating immune complexes in diabetics with and without microangiopathy. Clin Exp Immunol 1983;52:575-80.

13 Bodansky HJ, Wolf E, Cudworth AG, et al. Genetic and immunologic factors in microvascular disease in type 1 insulin dependent diabetes. Diabetes 1982;31:70-4.

14 Whittingham S, Mathews JD, Schanfield MS, et al. Interactive effect of Gm allotypes and HLA B locus antigens on the human antibody response to a bacterial antigen. Clin Exp Immunol $1980 ; 40: 8-15$

(Accepted 10 December 1985)

\title{
Prostacyclin deficiency in a young woman with recurrent thrombosis
}

\author{
JOHN G LANHAM, MICHAEL LEVIN, ZARIN BROWN, AZZIZ E GHARAVI, \\ PAUL A THOMAS, GILLIAN C HANSON
}

\begin{abstract}
A young woman with recurrent deep venous thromboses and spontaneous abortions was studied. She suffered an ovarian infarction followed by aortic thrombosis and renal failure. Evidence for deficient prostacyclin production was found and she responded to treatment with a prostacyclin infusion. This syndrome is identical with that seen in women with the lupus anticoagulant, but the lupus anticoagulant was not detected and no other cause was identified.
\end{abstract}

\section{Introduction}

A syndrome of recurrent deep venous and arterial thromboses with recurrent spontaneous abortions has been described in young women with the lupus anticoagulant. ${ }^{1}$ The lupus anticoagulant may be implicated in the pathogenesis of this syndrome through suppression of prostacyclin production. ${ }^{23}$ We report a young woman with a similar syndrome, when life threatening arterial thrombosis occurred. No prostacyclin production by her own arterial tissue could be shown and reduced prostacyclin activity was found when umbilical cord artery and rat aortic tissue were incubated in her plasma. She did not have the lupus anticoagulant or any other disorder associated with arterial thrombosis.

Whipps Cross Hospital, London E11 1NR

JOHN G LANHAM, MB, MRCP, consultant physician and rheumatologist

PAUL A THOMAS, MB, FRCS, consultant surgeon

GILLIAN C HANSON, MB, FRCP, consultant physician

Hammersmith Hospital, London W12 0HS

AZZIZ E GHARAVI, MD, honorary clinical assistant

Institute of Child Health, London WC1N IEM

MICHAEL LEVIN, MB, MRCP, lecturer

Renal Unit, Guy's Hospital, London SE1 9RT

ZARIN BROWN, BSC, research technician

Correspondence to: Dr Lanham.

\section{Case report}

A 25 year old woman with no family history of thrombotic disease first took the oral contraceptive pill when aged 17, and six months later suffered bilateral deep vein thromboses and a pulmonary embolus. At the age of 23 she had a spontaneous abortion at eight weeks. One year later a second pregnancy was complicated by a left leg deep vein thrombosis at 26 weeks, and this pregnancy terminated with an intrauterine death at 31 weeks. Placental histology showed vascular insufficiency to be the cause. A third pregnancy ended in spontaneous abortion at 24 weeks, despite treatmen with subcutaneous heparin for the first 16 weeks followed by treatment with warfarin. Subcutaneous heparin (10000 units daily) was begun again after the abortion, but 10 days later she developed a right iliofemoral vein thrombosis. The heparin dose was increased, but a fortnight thereafter she required a laparotomy because of a ruptured right tubo-ovarian cyst; histological examination showed infarcted ovarian and paraovarian tissues.

Three weeks later, while still receiving heparin, she presented with an ischaemic left foot with absent leg pulses and an abdominal aortic bruit. At emergency laparotomy thrombus was found in the aorta and both iliac and femoral arteries (figure). This was removed and she was again fully heparinised. Postoperatively she developed acute renal failure and subsequently septicaemia and required ventilation. Her renal failure was attributed to extension of the thrombus into the renal arteries and a prostacyclin (epoprostenol) infusion was therefore begun. Thereafter, renal function improved rapidly as did perfusion of the right foot. The left foot remained ischaemic and was eventually amputated below the knee. On reduction of the dose of epoprostenol she developed severe bilateral leg oedema, which was ascribed to a partial inferior venacaval thrombosis. With an increased dose the oedema gradually subsided and the epoprostenol and heparin infusions were stopped a month later.

Treatment with warfarin, paediatric aspirin, and dipyridamole was started. Renal function returned to normal. At no time were there any clinical features to suggest a connective tissue disease or vasculitis.

Full blood count and erythrocyte sedimentation rate were normal during her third pregnancy but the platelet count rose from 250 to $640 \times 10^{9} / 1$ at the time of the aortic thrombosis. Before treatment her prothrombin time and partial thromboplastin time were normal. To confirm that she did not have the lupus anticoagulant a plasma sample was fractionated and lupus anticoagulant activity was sought, but not found, in the IgG and IgM fractions (method of Boey et $a l^{1}$ ). Fibrinogen, fibrinogen degradation products, and antithrombin III were also normal. Protein $\mathrm{C}$ concentration (chromogenic assay) was depressed but compatible with treatment with warfarin and did not suggest a congenital deficiency. No antibodies to nuclear antigens, deoxyribonucleic acid, extractable nuclear antigens, or cardiolipin were detected. Lipid concentrations were normal and screening for homocystinuria was negative. Histological examination of the aorta and tibial artery showed intraluminal thrombosis, but the vessel wall was normal, and no evidence of atheroma, vasculitis, or thrombotic thrombocytopenic purpura was found. 


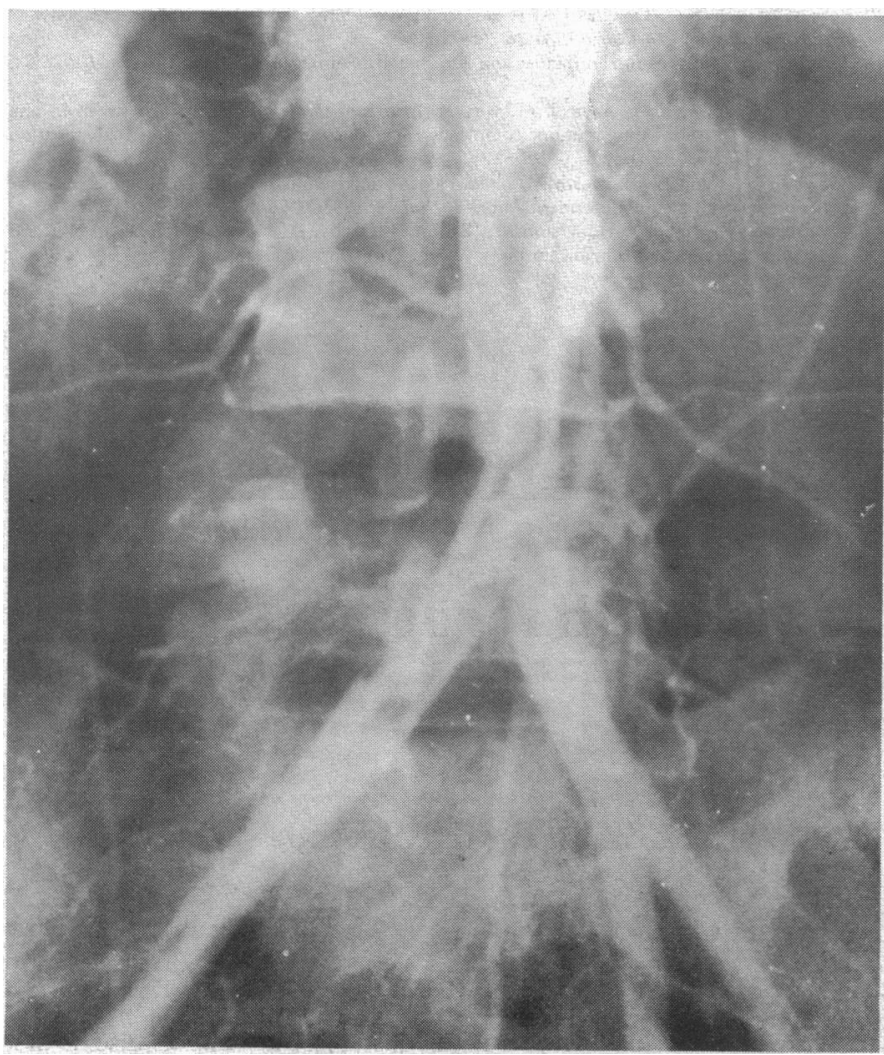

Arteriogram showing thrombus at aortic bifurcation.

Prostacyclin production by arterial segments obtained from the amputated leg was assessed as described previously. ${ }^{4}$ Segments $(2 \mathrm{~cm}$ long) of arterial endothelium were cleared of subcutaneous tissue and kept in ice cold saline buffered with phosphate for two hours until testing. These segments were incubated in both $500 \mu \mathrm{l}$ of her plasma and a similar quantity of normal plasma for 15 minutes. An aliquot of $100 \mu \mathrm{l}$ of the supernatant was removed and added to $300 \mu \mathrm{l}$ of normal plasma rich in platelets. The mixture was challenged with $4 \mu \mathrm{mol}$ adenosine diphosphate, and the amount of prostacyclin produced by the arterial segments was assessed by the degree of inhibition of platelet aggregation. No prostacyclin like activity was detected when the patient's arterial segments were incubated with either her own or normal plasma, whereas segments of artery taken from three other patients at necropsy and tested under comparable conditions produced prostacyclin. Further experiments were performed by incubating the patient's plasma and that of the control with rings of aorta from rats. Prostacyclin production by rat aortic tissue was diminished on incubation with her plasma in comparison with control plasma. This returned to normal after her recovery. Her plasma was also shown to induce strong aggregation of normal washed platelets.

\section{Discussion}

Thrombosis of the distal aorta is rare. It has been reported in a few premenopausal women in association with pregnancy and use of the oral contraceptive pill..$^{5}$ Solitary atherosclerotic lesions have been found in some of these women and heavy smoking implicated as a predisposing factor. ${ }^{5}$ Aortic thrombosis has also been reported in the context of homocystinuria, antithrombin III deficiency, and vasculitis. ${ }^{6.8}$

Young women with recurrent venous and arterial thrombosis and recurrent spontaneous abortion form a distinct subset of patients, some of whom have systemic lupus erythematosus. The lupus anticoagulant is usually present in this clinical setting and tests for anticardiolipin antibodies are positive.' The pathogenesis of this syndrome has yet to be established, but the favoured explanation implicates the lupus anticoagulant as a suppressor of prostacyclin release..$^{23}$ The lupus anticoagulant is an immunoglobulin, IgG, IgM, or both, that acts by inhibition of the phospholipid portion of the prothrombin activator complex. By binding to these phospho- lipids it prolongs the partial thromboplastin time. Its binding to cardiolipin is responsible for the false positive tests for syphilis seen in patients with sytemic lupus erythematosus. ${ }^{9}$ The lupus anticoagulant is thought to inhibit prostacyclin production by interfering with the release of arachidonic acid (the substrate for prostacyclin) from phospholipids in the cell membrane. Prostacyclin is the most powerful known inhibitor of platelet aggregation and a potent vasodilator and plays an important part in preventing thrombosis and maintaining placental blood flow. ${ }^{11}$ Inhibition of its release by the lupus anticoagulant would explain the paradoxical association of the lupus anticoagulant with thrombotic disease as well as the tendency to spontaneous abortion.

The disease in our patient closely resembled that seen in women with the lupus anticoagulant. We found no evidence, however, of the lupus anticoagulant or anticardiolipin antibodies. Nevertheless, we showed that her plasma failed to support prostacyclin production when incubated with segments of rat aorta or human umbilical cord artery and that her arterial endothelium produced no prostacyclin. This suggests a mechanism in our patient similar to that in patients with the lupus anticoagulant syndrome and implicates prostacyclin deficiency as a cause of her thrombotic events and spontaneous abortions.

Corticosteroid treatment of patients with the lupus anticoagulant syndrome has recently resulted in several successful pregnancies. ${ }^{12}$ In those who suffer recurrent venous thrombosis treatment with heparin and warfarin is usually effective. But the successful treatment of our patient with epoprostenol when preventive treatment with heparin and warfarin had failed, suggests the use of this agent in other cases when this clinical syndrome is associated with arterial thrombosis or extensive venous thrombosis, even if the lupus anticoagulant is not detectable.

We thank Mr Mackie, department of pathology, Middlesex Hospital, for measuring the protein $\mathrm{C}$ concentrations and Dr E N Harris, St Thomas's Hospital, for testing for anticardiolipin antibodies.

\section{References}

1 Boey LM, Colaco CB, Gharavi AE, Elkon KB, Loizou S, Hughes GRV. Thrombosis in systemic lupus erythematosus: striking association with the presence of circulating "lupus anticoagulant." BrMed f 1983;287:1021-3.

2 Carreras LO, Vermylen JG. "Lupus" anticoagulant and thrombosis: possible role of inhibition of prostacyclin formation. Thromb Haemost 1982;48:38-40.

3 Carreras LO, Defreyn G, Machin SJ, et al. Arterial thrombosis intra-uterine death and "lupus" anticoagulant: detection of immunoglobulin interfering with prostacyclin formation. Lance $1981 ; \mathrm{i}: 244-6$.

4 Levin M, Elkon KB, Noakes TGC, et al. Inhibitor of prostacyclin production in sporadic haemolytic-uraemic syndrome. Arch Dis Child 1983;58:703-8.

5 Van Vroonhaven TJMV. Intermittent claudication in pre-menopausal women: a correlation with the long-term use of oral contraceptives. I Cardiovasc Surg (Torino) 1977;18:291-5.

6 Newman G, Mitchell JRA. Homocystinuria presenting as multiple arterial occlusions. $Q \mathcal{J ~ M e d}$ 1984;210:251-8.

7 Shapiro ME, Salzman EW. Acute aortic thrombosis in anti-thrombin III deficiency. JAMA 1981;245:1759-61

8 Sen PK, Kinare SG, Engineer SD, Parukar GB. The middle aortic arch syndrome. Br Heart $\mathcal{f}$ 1963;25:610-8.

9 Harris EN, Gharavi AE, Boey ML, et al. Anticardiolipin antibodies: detection by radioimmunoassay and association with thrombosis in systemic lupus erythematosus. Lancet 1983;ii: 1211-4.

10 Thiagarajan P, Shapiro SS, De Marco L. Monoclonal immunoglobulin M coagulation inhibitor with phospholipid specificity. Mechanism of a lupus anticoagulant. $\mathcal{J}$ Clin Invest 1980;66:

11 Stuart MJ, Clark DA, Sunderii SG, et al. Decreased prostacyclin production: a characteristic of chronic placental insufficiency syndrome. Lancet 1981;i:1126-8.

12 Lubbe WF, Butler WS, Palmer SJ, Liggins GC. Fetal survival after prednisone suppression of maternal lupus anticoagulant. Lancet 1983;i:1361-3.

(Accepted 22 October 1985)

\section{YEARS AGO}

A firm of manufacturers of "non-alcoholic" wines, Messrs. Turley, who are said to have done an extensive business, were lately summoned by the excise authorities at Birmingham for selling intoxicating liquors without a licence. These wines (port and sherry), though guaranteed free from alcohol, were found, on analysis at Somerset House, to contain respectively 17 and 19 per cent. of alcohol. (British Medical fournal 1886;i:123.) 